\title{
Emergency Department Use by Centenarians: The 2008 Nationwide Emergency Department Sample
}

\author{
Matthew R. Carey; Embry M. Howell, PhD; Megan Colleen McHugh, PhD \\ Suggested citation for this article: Carey MR, Howell EM, McHugh MC. Emergency Department Use by Centenarians: The \\ 2008 Nationwide Emergency Department Sample. Prev Chronic Dis 2013;10:120006. DOI: \\ http://dx.doi.org/10.5888/pcd10.120006 圈.
}

PEER REVIEWED

\section{Abstract}

Introduction

Older adults have higher rates of emergency department use than do younger adults, and the number of centenarians is expected to increase. The objective of this study was to examine centenarians' use of the emergency department in the United States, including diagnoses, charges, and disposition.

\section{Methods}

The 2008 Nationwide Emergency Department Sample, Healthcare Cost and Utilization Project, Agency for Healthcare Research and Quality provided encounter-level data on emergency department visits and weights for producing nationwide estimates. From this data set, we collected patient characteristics including age, sex, primary diagnosis, and disposition. We used $\chi^{2}$ tests and $t$ tests to test for significant differences among people aged 80 to 89,90 to 99 , and 100 years or older.

\section{Results}

Centenarians had a lower rate of emergency department use than those aged 90 to 99 (736 per 1,000 vs 950 per 1,000; $P<.05)$. We found no significant difference in use between centenarians and those aged 80 to 89 . The most common diagnoses for centenarians were superficial injuries (5.8\% of visits), pneumonia (5.1\%), and urinary tract infections (5.1\%). Centenarians were more likely to visit the emergency department for fall-related injuries (21.5\%) than those aged 80 to $89(14.1 \% ; P<.05)$ and 90 to $99(18.7 \% ; P<.05)$. Centenarians were more likely to die in the emergency department $(2.0 \%)$ than were those aged 80 to $89(0.6 \% ; P<.05)$ and 90 to $99(0.7 \% ; P<.05)$.

\section{Conclusion}

Centenarians in emergency departments in the United States have different diagnoses, conditions, and outcomes than other older Americans.

\section{Introduction}

The number of centenarians in the United States is projected to increase more than $700 \%$ during the coming decades, from 79,000 in 2008 to more than 600,000 in 2050 (1). Although in absolute terms these increases are small, they indicate that this minority group may one day strongly influence health policy. This growth has led to research on the health outcomes of these eldest members of society (2-10). Studies have noted the unique health care needs and use patterns of centenarians compared with other older populations. Many centenarians, for instance, have been able to delay or avoid chronic conditions commonly associated with old age such as heart disease and stroke (8). Centenarians also have lower instances of cancer $(9,10)$. Despite this body of literature on centenarians and many studies on emergency department use by older adults in general, there is little research on emergency department use by centenarians (11-13).

Understanding the patterns of use and etiology of emergency department visits among centenarians is important for several reasons. First, emergency physician and nurse training can use this information to tailor services to the needs of this population, which will represent a greater share of visits in the future. Second, hospital administrators can use 
this information for capacity planning, which is crucial to the problem of crowding in emergency departments nationwide (14). This problem may be exacerbated by the growing number of centenarians who may be more likely to be admitted to the hospital. Third, this information may be used to develop targeted services to prevent emergency department visits by centenarians. Understanding why centenarians visit the emergency department will also allow health care administrators to determine the appropriateness of such visits and design programs that could address the primary causes of emergency department use among this group, thereby reducing the number of visits and slowing the rise of health care costs. The objective of this study was to describe centenarians' use of emergency department services, including rates of use, primary diagnoses, charges, and disposition.

\section{Methods}

We used the 2008 Nationwide Emergency Department Sample (NEDS) to collect data on emergency department use by the oldest old (15). NEDS is a nationwide data set created as part of the Healthcare Cost and Utilization Project (HCUP), a federal-state-industry partnership sponsored by the Agency for Healthcare Research and Quality (AHRQ) (16). As the largest emergency department data set available, it is useful for studying emergency department use by centenarians, given that they comprise such a small percentage of the population. The data set is a $20 \%$-stratified sample of 980 emergency departments in 24 states in the United States (16). NEDS provides information on disposition, diagnoses, procedures, charges, patient characteristics (eg, age, sex, geographic residence [Northeast, Midwest, South, and West]), and hospital emergency department characteristics (eg, trauma center, urban/rural location, region, teaching status) for more than 25 million visits annually (16). From this sample, researchers can create nationwide estimates of emergency department visits by using discharge weights provided in NEDS (16).

For this study, we grouped emergency department visits according to age, sex, US Census region, urban or rural residence of the patient, disposition from the emergency department, and primary diagnosis. NEDS uses the 6category urban/rural classification system designed by the National Center for Health Statistics (NCHS), which can be mapped onto the United States Department of Agriculture's 2003 Urban Influence Codes (UICs) to classify patients' residences as urban or rural (16). We defined a patient's residence as urban if the person's county of residence had an NCHS code of 1 to 4 , corresponding to a UIC of 1 or 2 (16). These 2 UICs encompass all metropolitan counties in the United States, as defined by the Office of Management and Budget's metro/non-metro county categorical system (17). We classified patients living in counties with any other UICs as rural patients. We calculated average emergency department charges for each age cohort based on the charge data provided in NEDS for each visit. NEDS lacks information on emergency department charges for $18 \%$ of emergency department visits (16). Observations that lacked data on emergency department charges were excluded when we calculated average emergency department charges for each age cohort. Although NEDS provides ICD-9-CM (International Classification of Diseases, Ninth Revision, Clinical Modification) codes for up to 15 diagnoses per emergency department visit, we used only the first diagnosis listed for this analysis. According to AHRQ, the first-listed diagnosis for an emergency department record indicates the "code for the diagnosis, condition, problem or other reason for encounter/visit shown in the medical record to be chiefly responsible for the services provided" (18). We applied the Clinical Classifications Software (CCS) - a means of grouping ICD-9-CM codes developed as part of the HCUP - to the primary diagnosis ICD-9-CM codes found in the NEDS to group these diagnoses into meaningful categories (19). We identified the 15 most common primary admitting diagnoses in our sample. In addition to the diagnostic codes, NEDS provides separate external cause-of-injury codes for people who visit the emergency department because of injury. We used the CCS code E2603 to determine the number of patients visiting the emergency department because of falls.

To produce the population denominators needed for constructing use rates, we used the 2008 Population Projections created by the US Census Bureau (20). We were not able to use population estimates derived from national surveys such as the American Community Survey or Current Population Survey because their small sample sizes do not allow for accurate estimates of the number of centenarians. The 2008 Population Projections provided total population estimates and sex-specific estimates for each of the age cohorts used in the study: aged 80 to 89 years, aged 90 to 99 years, and aged 100 years or older (centenarians). Because these population projections do not provide detailed information on the US population by census region or urban/rural residence, we applied the proportions from the 2000 Census Summary File 4 data set to the 2008 population projections (21). Our assumption was that older adults have a low rate of migration and that any bias caused by this assumption would be limited (22). The NEDS urban/rural classification system for patients was also used to determine the urban and rural population totals for each age cohort.

We used SAS 9.2 (SAS Institute Inc, Cary, North Carolina) for all data analyses. Because of the complex sampling design and weighting used in NEDS, the NEDS documentation provides detailed information on variance calculations necessary for constructing confidence intervals and testing for significance. The supplementary hospital file allows standard errors to be calculated for subsets of NEDS (23). We used $\chi^{2}$ tests to test for significant differences in the distribution of dispositions from the emergency department and diagnoses by age cohort. We used $t$ tests to test for significant differences in the rates of emergency department use by age cohort. For all tests, we used $P<.05$ as the significance level. Because we made multiple comparisons when analyzing the dispositions and diagnoses of the 3 cohorts, we applied the Bonferroni correction to the significance level, using $P<.0083$ as the adjusted significance 
level when comparing dispositions and $P<.0033$ as the adjusted significance level when comparing diagnoses, both of which are equivalent to $P<.05$ for a single test.

\section{Results}

In 2008 nationwide, there were an estimated 7,061,763 emergency department visits among people aged 80 to 89; 1,786,792 visits among those aged 90 to 99; and 52,265 visits among those aged 100 or older. The overall use rate (Table 1) for centenarians was significantly lower than the rate for people aged 90 to 99 (736 per 1,000 vs 950 per 1,000). We found no significant difference between the use rates of centenarians and those aged 80 to 89 (736 per 1,000 vs 766 per 1,000). We found a significant difference between use rates of male and female centenarians (952 per 1,000 vs 687 per 1,000). This difference was much larger than the difference for the other 2 age cohorts: 766 per 1,000 for both sexes aged 80 to 89 and 987 per 1,00o for men and 936 per 1,00o for women aged 90 to 99 . We found no significant difference between the use rates of centenarians and those aged 80 to 89 for any of the 4 geographic areas. Centenarians had fewer visits per 1,000 than those aged 90 to 99 in the Northeast (705 per 1,000 vs 922 per 1,000) and South (789 per 1,000 vs 997 per 1,000).

All age cohorts had more visits per 1,00o in urban areas than in rural areas, but these differences were significant only for centenarians (743 per 1,000 vs 619 per 1,000). Those aged 90 to 99 had significantly higher use rates than centenarians in both urban ( 971 per 1,00o vs 743 per 1,000$)$ and rural $(865$ per 1,000 vs 619 per 1,00o) areas. When we compared use rates between those aged 80 to 89 and those aged 100 or older, we found a significant difference only for rural areas: 739 per 1,000 for those aged 80 to 89 and 619 per 1,00o for those aged 100 or older.

Although centenarians had the highest emergency department charges per visit, the differences among the age cohorts were not significant. Centenarians had average emergency department charges of \$2,227 per visit, compared with $\$ 2,123$ for those aged 80 to 89 and $\$ 2,032$ for those aged 90 to 99 .

Significantly more centenarians were transferred to a skilled nursing facility (6.9\%) than were those aged 90 to 99 (5.4\%) or 80 to 89 (3.1\%) (Table 2 ). In addition, significantly more centenarians died in the emergency department (2.0\%) than did those aged 90 to $99(0.7 \%)$ or 80 to $89(0.6 \%)$.

We found significant differences by age cohort in the 15 most common primary admitting diagnoses (Table 3). The most common diagnosis for centenarians was superficial injury or contusion (5.8\%), whereas the most common diagnosis for those aged 80 to 89 and 90 to 99 year was congestive heart failure (nonhypertensive). Other common diagnoses for centenarians were pneumonia (5.1\%) and urinary tract infections (5.1\%). Centenarians had a significantly lower percentage of visits for cardiac dysrhythmias (1.8\%), nonspecific chest pain (1.8\%), syncope (1.7\%), and chronic obstructive pulmonary disease and bronchiectasis (1.1\%) than those aged 80 to 89 and 90 to 99 . According to the external cause-of-injury code for falls, centenarians had a significantly greater percentage of visits resulting from falls (21.5\%) than did those aged 90 to $99(18.7 \%)$ or 80 to $89(14.1 \%)$.

\section{Discussion}

Although centenarians had lower rates of emergency department use than other older persons, a significantly greater proportion of centenarians died in the emergency department. The elderly visit the emergency department for different reasons than younger people (12). Our study indicated differences in patterns of emergency department use in the elderly cohort - specifically, differences between centenarians and those aged 80 to 89 and 90 to 99 . The distribution of primary diagnoses indicates that centenarians visit the emergency department with needs that are different from those of the younger 2 age cohorts.

Other research on the health status of centenarians and the oldest old may give clues as to the causes for these differences in emergency department use. Some studies show that centenarians seem to delay or avoid typical agerelated diseases and disorders, including cancer (8-10). The ability to reach extreme ages while avoiding common chronic conditions may explain why centenarians are less likely to visit the emergency department for cardiac dysrhythmias, chronic obstructive pulmonary disease, chest pain, and acute cerebrovascular disorders. Other studies, however, found high rates of certain chronic conditions, such as hypertension and heart disease, so no definitive conclusions can be made $(24,25)$.

Although many centenarians may have avoided chronic conditions, they are not immune from the frailty associated with old age, which may increase the risk of infections such as pneumonia and influenza (26). This increased susceptibility to infection is consistent with the findings of our study, which shows that centenarians have proportionally more emergency department visits for pneumonia than those aged 80 to 89 or 90 to 99 .

Our study indicates that centenarians are more likely than those aged 80 to 89 or 90 to 99 to visit the emergency department for falls. Higher proportions of visits for "superficial injury, contusion" and "open wounds of head, neck, and trunk" among people aged 100 or older than among the younger 2 age cohorts also support this finding. One study 
found that centenarians have low scores on measures of daily social and productive functioning (27). Another study found a correlation between a higher prevalence of fractures and a low level of functional ability among centenarians, although the authors cautioned that this finding may be only an artifact of the increased susceptibility of elderly people to sustaining fractures (25). Taken together, our data on emergency department visits for centenarians conforms to the findings of other research on the health characteristics of centenarians.

Our study has several limitations. First, because the 2008 NEDS data set provides information only on about half of all emergency department visits and then weights these to create national estimates, the use rates calculated in our study may have over- or underestimated the true rates. This limitation was particularly worrisome when we examined the number of emergency department visits among centenarians. Because of their small fraction of the US population, centenarians likely are not distributed equally among areas included in NEDS and areas outside the NEDS survey area; this unequal distribution may have led to inaccurate national estimates when we applied the discharge weights. The second major limitation of this study is related to the construction of population denominators for the rates of emergency department use. The total population for each age cohort was based on projections produced by the US Census Bureau rather than estimates from a national survey conducted in 2008. This method could have led to inaccurate estimates of total populations for each age cohort, especially centenarians, because of the rapid growth of this age cohort. Using the regional population distributions from the 2000 Census to calculate the regional population for each age cohort added another potential source of error.

The NEDS database has several other limitations that constrained the number of analyses that could be conducted. First, NEDS provides encounter-level, rather than patient-level, data (16). Therefore, we could not use the NEDS to follow individual patients and determine how many visits were by the same person. Second, although NEDS provides the patient's destination after discharge, it provides no information on where the patient was before arriving at the emergency department (16). As a result, one relevant analysis - how many patients arrived from a skilled nursing facility - could not be performed. These limitations could be addressed by using emergency department data from hospitals, at the expense of the large sample size of centenarians found in NEDS, and may be an area for future research. Our research also indicates only whether centenarians are more likely to go to the emergency department for a particular condition, not whether they are more likely to contract that condition.

As the elderly population grows and hospital emergency departments become more crowded, understanding patterns of emergency department use among the oldest Americans is important. This research fills a void in the literature by analyzing the frequency, diagnoses, and charges for emergency department visits among the oldest old. Centenarians attend the emergency department for different conditions and have worse outcomes (ie, higher death rates) vis-à-vis slightly younger people. Although additional research must be done on the appropriateness of these visits as well as the relationship between the prevalence of a condition in the centenarian population and the number who visit the emergency department for that condition, our study indicates that it may be necessary to view this population as distinct from slightly younger people (ie, those aged 80 to 99) when characterizing emergency department use. As the centenarian population grows, health systems engineers and health care providers responsible for organizing and providing care in the emergency department will be able to use this and future research to ensure that the necessary equipment and properly trained staff are available to treat this population. Understanding the reasons for and outcomes of centenarians' visits to the emergency department will be necessary to inform discussions on efficient yet ethical allocations of these resources in emergency departments nationwide.

\section{Acknowledgments}

At the time of the study, Matthew Carey was affiliated with the Health Policy Center at the Urban Institute, Washington, DC. This research was conducted as part of the James A. Baker III Institute for Public Policy Summer in DC Undergraduate Internship Program. No outside funding was used for this project. We especially thank the Health Policy Center at the Urban Institute for their support and feedback on this research, and we are indebted to Tim Waidmann from the Urban Institute for his helpful comments on drafts of this paper. We also thank our anonymous reviewers at Preventing Chronic Disease for taking the time to evaluate the manuscript and provide suggestions that improved the quality of this article.

\section{Author Information}

Corresponding Author: Matthew R. Carey, Jones Graduate School of Business, Rice University, 6100 Main St, Houston, TX 77005. Telephone: 210-748-4242. E-mail: mcarey@rice.edu.

Author Affiliations: Embry M. Howell, Health Policy Center, the Urban Institute, Washington, DC; Megan Colleen McHugh, Center for Healthcare Studies and Department of Emergency Medicine, Northwestern University, Feinberg School of Medicine, Chicago, Illinois. 


\section{References}

1. US Census Bureau. Projected population by single year of age, sex, race, and Hispanic origin for the United States: July 1, 2000 to July 1, 2050. Washington (DC): US Department of Commerce; 2008.

http://www.census.gov/population/www/projections/summarytables.html. Accessed July 31, 2011.

2. Gareri P, Lacava R, Rossi MG, Iorio C, Galasso MA, Pansini L, et al. Hypertension in a group of centenarians. Arch Gerontol Geriatr 1996;5 Suppl 1:373-6. CrossRef 圈 PubMed 圈

3. Jachymczyk T, Cwynar M, Zyczkowska J, Klichraczka A, Wizner B, Grodzicki T. Arterial stiffness is increased in hypertensive centenarians. Blood Press 2006;15(6):362-6. CrossRef 国 PubMed 圈

4. Konttinen N, Rosenberg PH. Outcome after anesthesia and emergency surgery in patients over 100 years old. Acta Anaesthesiol Scand 2006;50(3):283-9. CrossRef 国 PubMed 国

5. Krishnan E, Fries JF, Kwoh CK. Primary knee and hip arthroplasty among nonagenarians and centenarians in the United States. Arthritis Rheum 2007;57(6):1038-42. CrossRef 圈 PubMed 圈

6. Oliver CW, Burke C. Hip fractures in centenarians. Injury 2004;35(10):1025-30. CrossRef 因 PubMed 圈

7. Wilson MT, Crawford KL, Shabot MM. Intensive care unit outcomes of surgical centenarians: The "oldest old" of the new millennium. Am Surg 2000;66(9):870-3. PubMed 圈

8. Evert J, Lawler E, Bogan H, Perls T. Morbidity profiles of centenarians: Survivors, delayers, and escapers. J Gerontol A Biol Sci Med Sci 2003;58(3):232-7. CrossRef 国 PubMed 国

9. Miyaishi O, Ando F, Matsuzawa K, Kanawa R, Isobe K. Cancer incidence in old age. Mech Ageing Dev 2000;117(13):47-55. CrossRef 塄 PubMed 圈

10. Arnold J, Dai J, Nahapetyan L, Arte A, Johnson MA, Hausman D, et al. Predicting successful aging in a population -based sample of Georgia centenarians. Curr Gerontol Geriatr Res 2010;2010:1-9.

11. Aminzadeh F, Dalziel WB. Older adults in the emergency department: A systematic review of patterns of use, adverse outcomes, and effectiveness of interventions. Ann Emerg Med 2002;39(3):238-47. CrossRef 圈 PubMed 因

12. Grief CL. Patterns of ED use and perceptions of the elderly regarding their emergency care: A synthesis of recent research. J Emerg Nurs 2003;29(2):122-6. CrossRef 圈 PubMed 圈

13. Samaras N, Chevalley T, Samaras D, Gold G. Older patients in the emergency department: a review. Ann Emerg Med 2010;56(3):261-9. CrossRef 圈 PubMed 圈

14. National Research Council. Hospital-based emergency care: at the breaking point. Washington (DC): The National Academies Press; 2007.

15. Agency for Healthcare Research and Quality. Healthcare Cost and Utilization Project (HCUP) - The Nationwide Emergency Department Sample for the year 2008. Rockville (MD): Agency for Healthcare Research and Quality; 2010.

16. Agency for Healthcare Research and Quality. Introduction to the HCUP Nationwide Emergency Department Sample (NEDS) 2008. Rockville (MD): Agency for Healthcare Research and Quality; 2010. http://www.hcupus.ahrq.gov/db/nation/neds/NEDS2008Introductionv3.pdf. Accessed July 22, 2013.

17. US Department of Agriculture, Economic Research Service. Urban influence codes: documentation. Washington (DC): Economic Research Service [updated $2012 \mathrm{Jul} 5]$. http://www.ers.usda.gov/data-products/urban-influence -codes/documentation.aspx\#.UXoQhopv5_M. Accessed April 28, 2013.

18. Senathirajah M, Owens P, Mutter R, Nagamine M. Special study on the meaning of the first-listed diagnosis on emergency department and ambulatory surgery records. HCUP methods series report no. 2011-03. Rockville (MD): Agency for Healthcare Research and Quality; 2011. http://www.hcupus.ahrq.gov/reports/methods/methods.jsp. Accessed April 28, 2013.

19. Agency for Healthcare Research and Quality. Healthcare Cost and Utilization Project (HCUP) Clinical Classifications Software (CCS) for ICD-9-CM. Rockville (MD): Agency for Healthcare Research and Quality [updated 2013 Mar 28]. www.hcup-us.ahrq.gov/toolssoftware/ccs/ccs.jsp. Accessed April 28, 2013.

20. US Census Bureau. Projected population by single year of age, sex, race, and Hispanic origin for the United States: July 1, 2000 to July 1, 2050. Washington (DC): US Department of Commerce; 2008. http://www.census.gov/population/www/projections/summarytables.html. Accessed July 30, 2011.

21. US Census Bureau. United States Census 2000: Summary file 4. Washington (DC): US Department of Commerce; 2003. http://www.census.gov/census2000/SF4.html. Accessed July 30, 2011. 
Preventing Chronic Disease | Emergency Department Use by Centenarians: The 2008 Nat... Page 6 of 8

22. He W, Schachter J. Internal migration of the older population: 1995 to 2000 . Census 2000 special reports.

Washington (DC): US Census Bureau; 2003. http://www.census.gov/prod/2003pubs/censr-10.pdf. Accessed July 22, 2013.

23. Agency for Healthcare Research and Quality. HCUP calculating standard errors. Rockville (MD): Agency for Healthcare Research and Quality; 2012. www.hcup-us.ahrq.gov/tech_assist/tutorials.jsp. Accessed April 28, 2013.

24. Berzlanovich AM, Keil W, Waldhoer T, Sim E, Fasching P, Fazeny-Dörner B. Do centenarians die healthy? An autopsy study. J Gerontol A Biol Sci Med Sci 2005;60(7):862-5. CrossRef 圈 PubMed 国

25. Takayama M, Hirose N, Arai Y, Gondo Y, Shimizu K, Ebihara Y, et al. Morbidity of Tokyo-area centenarians and its relationship to functional status. J Gerontol A Biol Sci Med Sci 2007;62(7):774-82. CrossRef 恩 PubMed 圈

26. Motta M, Cardillo E, Vacante M, Malaguarnera M. Supercentenarians: the oldest people in the world. Indian J Med Res 2010;131:4-6. PubMed 圈

27. Motta M, Bennati E, Ferlito L, Malaguarnera M, Motta L. Successful aging in centenarians: myths and reality. Arch Gerontol Geriatr 2005;40(3):241-51. CrossRef 圈 PubMed 国

\section{Tables}

Table 1. Emergency Department Visit Rate per 1, ooo for People Aged 80 to 89, 90 to 99, and 100 Years or Older, by Sex, Region, and Urban/Rural Designation, a United States, 2008

\begin{tabular}{|c|c|c|c|}
\hline \multirow[b]{2}{*}{ Population Group } & \multicolumn{3}{|c|}{ Visit Rate per 1,000 ( $95 \%$ Confidence Interval) } \\
\hline & Age 80-89 $(n=7,061,763) b$ & Age 90-99 $(n=1,786,792) b$ & Age $\geq 100(n=52,265) b$ \\
\hline Total & $766(726-806)$ & $950 c(899-1,002)$ & $736(688-783)$ \\
\hline \multicolumn{4}{|l|}{ Sex } \\
\hline Male & 766c (724-808) & $987(924-1,050)$ & $952(837-1,067)$ \\
\hline Female & $766(727-805)$ & $936 c(887-985)$ & $687(645-729)$ \\
\hline \multicolumn{4}{|l|}{ Region } \\
\hline Northeast & $705(625-785)$ & $922 c(816-1,028)$ & $705(612-798)$ \\
\hline Midwest & $735(666-803)$ & $882(799-964)$ & $677(693-870)$ \\
\hline South & $824(747-902)$ & 997c $(897-1,098)$ & $789(693-884)$ \\
\hline West & $773(686-860)$ & $995(869-1,121)$ & $755(641-870)$ \\
\hline \multicolumn{4}{|c|}{ Urban/rural designation } \\
\hline Urban & $770(722-818)$ & $971 c(907-1,035)$ & $743(690-795)$ \\
\hline Rural & $739 c(693-784)$ & $865 c(807-923)$ & $619(555-684)$ \\
\hline
\end{tabular}

a The 2008 Nationwide Emergency Department Sample (15) was used to estimate the number of visits. The United States Census 2000: Summary File 4 (21), 2008 Population Projections (20), and US Department of Agriculture Urban Influence Codes (16) were used to estimate the population figures needed to derive rates.

b Weighted number of emergency department visits for each age cohort.

c Significantly different from rate for those aged $\geq 100(P<.05)$.

Table 2. Disposition From the Emergency Department for People Aged 80 to 89, 90 to 99, and 100 Years or Older, a United States, 2008

\begin{tabular}{|l|c|c|c|}
\hline \multirow{2}{*}{$\begin{array}{l}\text { Disposition from the Emergency } \\
\text { Department }\end{array}$} & \multicolumn{3}{|c|}{ Percentage of Total Visits for Each Age Cohort } \\
\cline { 2 - 4 } & $\begin{array}{c}\text { Age 80-89 }(\mathrm{n}= \\
\mathbf{7 , 0 6 1 , 7 6 3 ) b}\end{array}$ & $\begin{array}{c}\text { Age 90-99 }(\mathrm{n}= \\
1,786,792) \mathrm{b}\end{array}$ & $\begin{array}{c}\text { Age } \geq 100(\mathrm{n}= \\
52,265) \mathrm{b}\end{array}$ \\
\hline
\end{tabular}




\begin{tabular}{|c|c|c|c|}
\hline \multirow[b]{2}{*}{$\begin{array}{l}\text { Disposition from the Emergency } \\
\text { Department }\end{array}$} & \multicolumn{3}{|c|}{ Percentage of Total Visits for Each Age Cohort } \\
\hline & $\begin{array}{c}\text { Age } 80-89(n= \\
7,061,763)^{b}\end{array}$ & $\begin{array}{c}\text { Age } 90-99(\mathrm{n}= \\
1,786,792)^{\mathrm{b}}\end{array}$ & $\begin{array}{c}\text { Age } \geq 100(n= \\
52,265)^{b}\end{array}$ \\
\hline $\begin{array}{l}\text { Admitted or transferred to another } \\
\text { hospital }\end{array}$ & 49.0 & $53.3 \mathrm{c}$ & 50.7 \\
\hline Transferred to a skilled nursing facility & $3.1 \mathrm{c}$ & $5.4 \mathrm{c}$ & 6.9 \\
\hline Transferred to home health care & 0.3 & 0.4 & 0.4 \\
\hline Discharged & $46.2 \mathrm{c}$ & 39.7 & 38.5 \\
\hline Died & $0.6 c$ & $0.7 \mathrm{c}$ & 2.0 \\
\hline $\begin{array}{l}\text { Other (against medical advice or } \\
\text { unknown) }\end{array}$ & $0.9 \mathrm{c}$ & $0.6 \mathrm{c}$ & 1.4 \\
\hline
\end{tabular}

a The 2008 Nationwide Emergency Department Sample (15) was used to estimate the number of emergency department visits by age cohort and disposition.

b Weighted number of emergency department visits for each age cohort.

c Significantly different from the percentage for those aged $\geq 100$ at a .05 level; because multiple comparisons were made, we applied the Bonferroni correction, using $P<.0083$ as the adjusted significance level.

Table 3. Percentage Distribution of Emergency Department Visits, by Age and Primary Admitting Diagnosis, a United States, 2008

\begin{tabular}{|c|c|c|c|}
\hline \multirow[b]{2}{*}{ Primary Admitting Diagnosis (CCS Identifier)b } & \multicolumn{3}{|c|}{ Percentage of Total Visits for Each Age Cohort } \\
\hline & $\begin{array}{l}\text { Age } 80-89(n= \\
7,061,763) c\end{array}$ & $\begin{array}{c}\text { Age 90-99 }(\mathrm{n}= \\
1,786,792)^{c}\end{array}$ & $\begin{array}{c}\text { Age } \geq 100(n= \\
52,265) c\end{array}$ \\
\hline Superficial injury, contusion (239) & $3.9 d$ & $4.7 \mathrm{~d}$ & $5 . \varepsilon$ \\
\hline $\begin{array}{l}\text { Pneumonia (except that caused by tuberculosis or } \\
\text { sexually transmitted disease) (122) }\end{array}$ & $3.5 \mathrm{~d}$ & $4.4 \mathrm{~d}$ & 5.1 \\
\hline Urinary tract infections (159) & $3.9 \mathrm{~d}$ & 4.8 & 5.1 \\
\hline Congestive heart failure, nonhypertensive (108) & $4.1^{\mathrm{d}}$ & 5.4 & 4.5 \\
\hline Open wounds of head, neck, and trunk (235) & $1.7 \mathrm{~d}$ & $2.2^{\mathrm{d}}$ & $3 . \varepsilon$ \\
\hline Hip fracture (226) & $1.9 \mathrm{~d}$ & 3.0 & 3.1 \\
\hline Septicemia (2) & $2.4^{d}$ & 3.0 & 3.0 \\
\hline Fluid and electrolyte disorders (55) & 2.0 & 2.4 & 2.4 \\
\hline Acute cerebrovascular disease (109) & 2.1 & $2.3 \mathrm{~d}$ & $1 . \varepsilon$ \\
\hline Cardiac dysrhythmias (106) & $3.0 \mathrm{~d}$ & $2.6 d$ & $1 . \varepsilon$ \\
\hline Nonspecific chest pain (102) & $3.2 \mathrm{~d}$ & $2.4 d$ & $1 . \varepsilon$ \\
\hline Syncope (245) & $2.3 \mathrm{~d}$ & $2.2 \mathrm{~d}$ & 1.7 \\
\hline Abdominal pain (251) & $1.8 \mathrm{~d}$ & 1.4 & 1.2 \\
\hline COPD and bronchiectasis (127) & $2.7 \mathrm{~d}$ & $1.8 \mathrm{~d}$ & 1.1 \\
\hline $\begin{array}{l}\text { Spondylosis, intervertebral disc disorders, back } \\
\text { problems (205) }\end{array}$ & $1.8 \mathrm{~d}$ & $1.5 \mathrm{~d}$ & 1.1 \\
\hline All other primary diagnoses & 59.7 & 56.2 & 56.3 \\
\hline Total diagnoses & 100.0 & 100.0 & 100.0 \\
\hline Falls (E2603)e & $14.1^{d}$ & $18.7 \mathrm{~d}$ & 21.5 \\
\hline
\end{tabular}

Abbreviations: CCS, Clinical Classifications Software; COPD, chronic obstructive pulmonary disease.

a The 2008 Nationwide Emergency Department Sample (NEDS) (15) was used to estimate the number of visits by age 
Preventing Chronic Disease | Emergency Department Use by Centenarians: The 2008 Nat... Page 8 of 8

cohort and primary diagnosis.

b The Nationwide Emergency Department Sample uses ICD-9-CM codes to label the admitting diagnoses for all patients (16). We applied the Clinical Classifications Software, a means of grouping ICD-9-CM codes, to create meaningful categories (19).

c Weighted number of emergency department visits for each age cohort.

d Significantly different from the percentage for those aged $\geq 100$ at a level of .05; because multiple comparisons were made, we applied the Bonferroni correction, using $P<.0033$ as the adjusted significance level.

e NEDS provides separate external cause-of-injury codes for people who visit the emergency department because of injury. We used CCS code E2603 to determine the number of patients visiting the emergency department because of falls.

The opinions expressed by authors contributing to this journal do not necessarily reflect the opinions of the U.S. Department of Health and Human Services, the Public Health Service, the Centers for Disease Control and Prevention, or the authors' affiliated institutions.

뎐 The RIS file format is a text file containing bibliographic citations. These files are best suited for import into bibliographic management applications such as EndNote $\mathbf{4}$, Reference Manager 圈, and ProCite 国. A free trial download is available at each application's web site.

For Questions About This Article Contact pcdeditor@cdc.gov

Page last reviewed: November 27, 2013

Page last updated: November 27, 2013

Content source: National Center for Chronic Disease Prevention and Health Promotion

Centers for Disease Control and Prevention 1600 Clifton Rd. Atlanta, GA 30333, USA 800-CDC-INFO (800-232-4636) TTY: (888) 232-6348 - Contact CDC-INFO 